\title{
Findings and recommendations from an international comparison of models and approaches for the estimation of radiological exposure to non-human biota
}

\author{
N.A. Beresford ${ }^{1}$, C.L. Barnett ${ }^{1}$, K. Beaugelin-Seiller ${ }^{2}$, J.E. Brown ${ }^{3}$,
} J.-J. Cheng ${ }^{4}$, D. Copplestone ${ }^{5}$, S. Gaschak ${ }^{6}$, J.L. Hingston ${ }^{5}$, J. Horyna ${ }^{7}$, A. Hosseini ${ }^{3}$, B.J. Howard ${ }^{1}$, S. Kamboj ${ }^{4}$, A. Kryshev ${ }^{8}$, T. Nedveckaite ${ }^{9}$, G. Olyslaegers ${ }^{10}$, T. Sazykina ${ }^{8}$, J.T. Smith ${ }^{11}$, D. Telleria ${ }^{12}$, J. Vives i Batlle ${ }^{13}$, T.L. Yankovich ${ }^{14}$, R. Heling ${ }^{15}$, M.D. Wood ${ }^{16}$ and C. $\mathrm{Yu}^{4}$

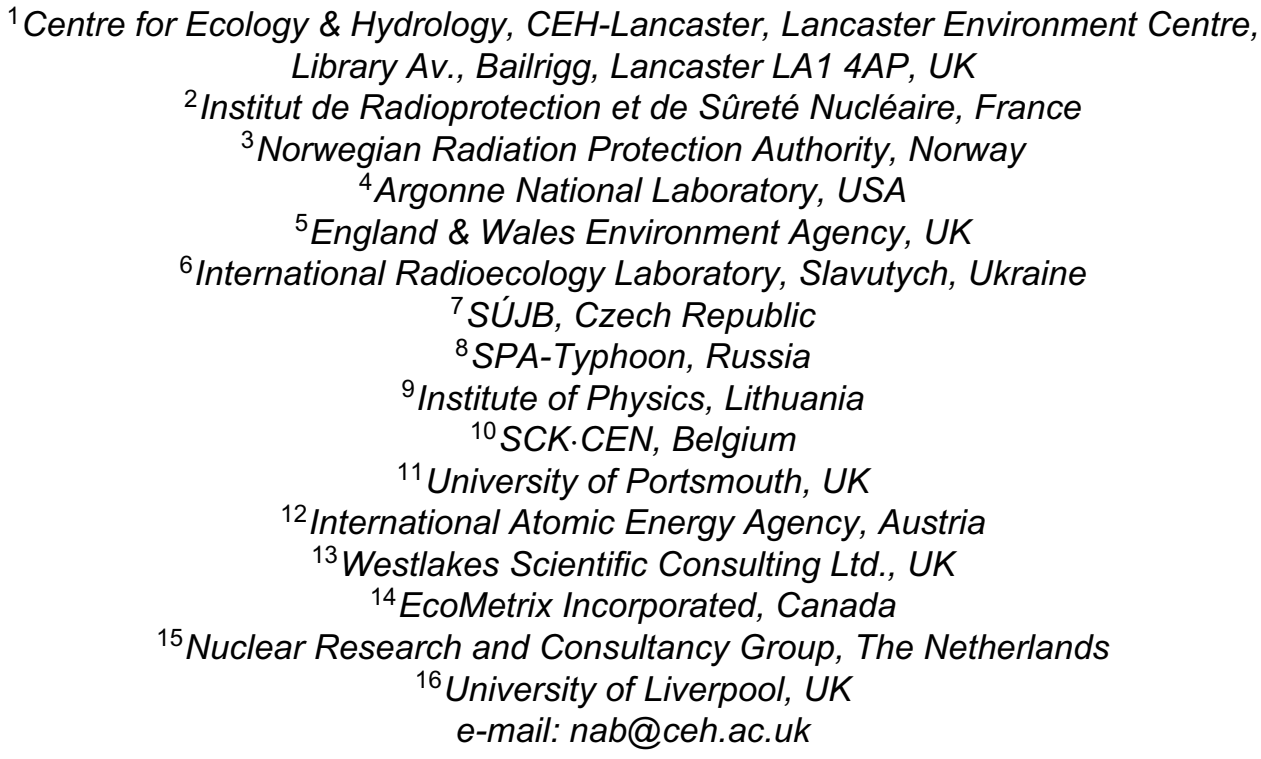

\begin{abstract}
There is general international acceptance of the need to demonstrate that the environment is protected from ionising radiation. In some countries requirements and guidelines for the protection of non-human biota are already in place. As a consequence a number of models and approaches have been proposed for the estimation of the exposure of non-human biota to ionising radiation. The IAEA EMRAS programme's Biota Working Group has conducted the most comprehensive intercomparison of the predictions of these approaches to date. In this paper, we present an overview of the activities of the Biota Working Group concentrating on its conclusions and recommendations.
\end{abstract}

\section{INTRODUCTION}

Internationally, the ICRP and IAEA are addressing environmental protection as an element of their revision of recommendations [1] and Basic Safety Standards, respectively. Some countries already have requirements and guidelines for the protection of non-human biota. For instance, in England and Wales, the requirement to assess impacts affecting Natura 2000 sites (under the Conservation (Natural Habitats) Regulations 1994, the UK implementation of the EU Birds and Habitats Directives) has been interpreted to include ionising radiation. In the USA, biota protection guidelines and dose rates are contained in USDOE Orders 5400.5 and 450.1 . 
In response to these developments, a number of models and approaches have been developed specifically to estimate the exposure of non-human biota to ionising radiations. Some countries (e.g. Canada, Finland, England and Wales, and the USA) are now using these within their national regulatory frameworks for (existing and proposed) nuclear and other sites that may release radioactivity to the environment. Software and/or documentation for some of these approaches are readily available and hence third parties are able to use them when conducting assessments.

The Biota Working Group (BWG; http://www-ns.iaea.org/projects/emras/emras-biota-wg.htm) was formed in 2004 by the IAEA as part of the Environmental Modelling for Radiation Safety (EMRAS) programme to address the gap of little validation and comparison of the different models and approaches. The primary objective of the BWG, was: 'to improve Member State's capabilities for protection of the environment by comparing and validating models being used, or developed, for biota dose assessment (that may be used) as part of regulatory process of licensing and compliance monitoring of authorised releases of radionuclides'.

In total, 15 models and approaches have been applied to one or more of the exercises conducted by the BWG. The models/approaches applied encompass those being developed, and in some instances, used in a regulatory context, in Belgium, Canada, France, Lithuania, Russia, the UK and the USA, as well as the outputs of recent EC EURATOM programmes. The participating models included those available to any interested user (RESRAD-BIOTA, the ERICA Tool, England and Wales Environment Agency R\&D 128 and FASSET(see http://www.ceh.ac.uk/protect/ pages/env protect radio.html for links to documentation and/or software for these approaches)) and in-house models being used/developed by various BWG participants (see IAEA [2] for a description of all participating models). Group members included modellers, regulators, industry and researchers.

In this paper, we concentrate on the main conclusions and recommendations arising from consideration of the BWGs activities; an overview of the early phases of the BWGs work can be found elsewhere [3].

\section{INTERCOMPARISON EXERCISES}

The BWG has conducted four intercomparison exercises to enable an evaluation of the basic components of the models:

- Dose conversion coefficients (DCCs) - participants were asked to estimate the unweighted absorbed dose rates for both internal and external exposure assuming an activity concentration of $1 \mathrm{~Bq} \mathrm{~kg}^{-1}$ in the organism or surrounding media, respectively. A selection of freshwater and terrestrial geometries proposed by the ICRP [4] for their Reference Animal and Plants (RAPs) were used for the exercises. Estimates were made for seven radionuclides $\left({ }^{3} \mathrm{H},{ }^{14} \mathrm{C},{ }^{60} \mathrm{Co},{ }^{90} \mathrm{Sr},{ }^{137} \mathrm{Cs},{ }^{238} \mathrm{U}\right.$ and $\left.{ }^{241} \mathrm{Am}\right)$ chosen to cover a range of energies and radiation types. The results of this exercise are described fully by Vives i Batlle et al. [5].

- Transfer - participants were required to estimate the whole-body activity concentration, of eighteen radionuclides, in seven terrestrial organisms (grass/herb, shrub, earthworm, herbivorous mammal, carnivorous mammal, rodent, bird egg) and twelve freshwater organisms (phytoplankton, zooplankton, macrophyte, benthic mollusc, small benthic crustacean, large benthic crustacean, pelagic fish, benthic fish, fish egg, amphibian, duck and mammal) assuming an activity concentration of $1 \mathrm{~Bq}$ per unit $\left(\mathrm{kg}, \mathrm{L}\right.$ or $\left.\mathrm{m}^{3}\right)$ of media (soil, water or air, respectively). The results of this exercise are evaluated in Beresford et al. [6].

Subsequently, two model-data comparisons (or scenario applications) were conducted (see IAEA [2] for details):

- Perch Lake - located on the AECL Chalk River Laboratories site (Ontario), Perch Lake has received chronic, low-level inputs of a number of radionuclides since the 1950s. Participants were supplied with ${ }^{90} \mathrm{Sr},{ }^{3} \mathrm{H},{ }^{60} \mathrm{Co}$ and ${ }^{137} \mathrm{Cs}$ activity concentrations in water and sediments for selected years to allow the comparison of predictions of whole-body activity concentrations in a range of biota, 
including different fish species, aquatic mammals, plants, aquatic reptiles, amphibians and a range of invertebrate species. Unweighted internal and external absorbed dose rates were also estimated.

- Chernobyl exclusion zone - participants were provided with soil activity concentrations $\left({ }^{90} \mathrm{Sr},{ }^{137} \mathrm{Cs}\right.$, ${ }^{241} \mathrm{Am}$ and $\mathrm{Pu}$-isotopes) and requested to make predictions of whole-body activity concentrations, and internal and external unweighted absorbed dose rates. Results were compared to available data for a range of biota types including: graminaceous vegetation; invertebrates; birds; a wide range of mammal species (from small rodents to deer and carnivorous species) and amphibians. Results from thermoluminescent dosimeters attached to small mammals were also available allowing a comparison with predicted external gamma dose rates.

\section{CONCLUSIONS}

\subsection{Dosimetry and transfer components of the models}

The exercise to compare predicted unweighted whole-body absorbed dose rates for a selection of the proposed ICRP RAP geometries demonstrated that all the 11 participating approaches generally estimated comparable internal dose rates even though different assumptions were made. The notable exception was as a consequence of different daughter products being included (e.g. one approach included ${ }^{234} \mathrm{U}$ in the estimation of the DCC for ${ }^{238} \mathrm{U}$ ). Variation was greater for the estimation of external dose rates, most notably for $\alpha$ - and $\beta$-emitters (e.g. from ${ }^{3} \mathrm{H}$, plutonium and some naturally occurring radionuclides). However, it is generally accepted that external exposure of biota by such emitters is of little radiological significance due to the low range of $\alpha$ - and $\beta$-emitters in matter.

The comparison of predicted activity concentrations in a range of freshwater and terrestrial biota by eight of the participating models, assuming $1 \mathrm{~Bq}$ per unit media, demonstrated considerably more variability than the comparison of unweighted dose estimates. For many radionuclide-reference organism combinations, variability in predictions covered three or more orders of magnitude. Predictions were often most variable for poorly studied organisms, such as fish egg, bird egg, duck, amphibian and aquatic mammals. Some of the more extreme variability could be explained by the use of 'guidance' methodology to provide values by a number of approaches in the absence of data. However, in some approaches, the guidance methodology is intended to be conservative and in most instances, it resulted in comparatively high (and hence conservative) predictions.

\subsection{Scenario applications}

The two scenario applications allowed model predictions to be compared to measured whole-body activity concentration data for a range of freshwater and terrestrial biota. Whilst some predictions deviated by more than three orders of magnitude from the available data, the majority of the models predicted activity concentrations in most organism types to within an order of magnitude. The understanding of the different models gained in the early phases of the work greatly aided interpretation of poor predictions and variability between the models.

The scenarios allowed comparison of the predictions of simple concentration ratio (CR) based approaches with more complex food-chain models under equilibrium conditions. Overall, the two approaches compared favourably. In the case of Perch Lake, three of the models which take into account water chemistry better predicted the transfer of ${ }^{90} \mathrm{Sr}$ to fish (Figure 1). However, it is possible that some of the CR-based approaches are erroneously parameterised such that they predict soft tissue and not whole-body activity concentrations.

The variability between the participating models in estimated dose rates could largely be explained by that in predicted whole-body activity concentrations. For the Chernobyl scenario, there was, surprisingly, less variability observed in the estimated total dose rates (typically less than an order of magnitude) than may have been anticipated from observed variation in predicted activity concentrations 
(typically at least three orders of magnitude) ${ }^{1}$. This was the consequence of some models underestimating for one radionuclide whilst over-predicting for another for the same organism and hence balancing out the overall prediction of dose. Total dose rate alone is, therefore, a poor output to compare in such model inter-comparisons.

For the Chernobyl scenario, predicted external dose rates generally contributed little to the overall total dose rate. Therefore, differences in assumptions with regard to occupancy contribute little to the overall variation in estimated dose rates. However, assumptions with regard to diet, and CR values used to predict the activity concentration in dietary components, were responsible for variation observed between those participating models which use food chain approaches rather than simple biota-media CR values.

\section{Freshwater Fishes}

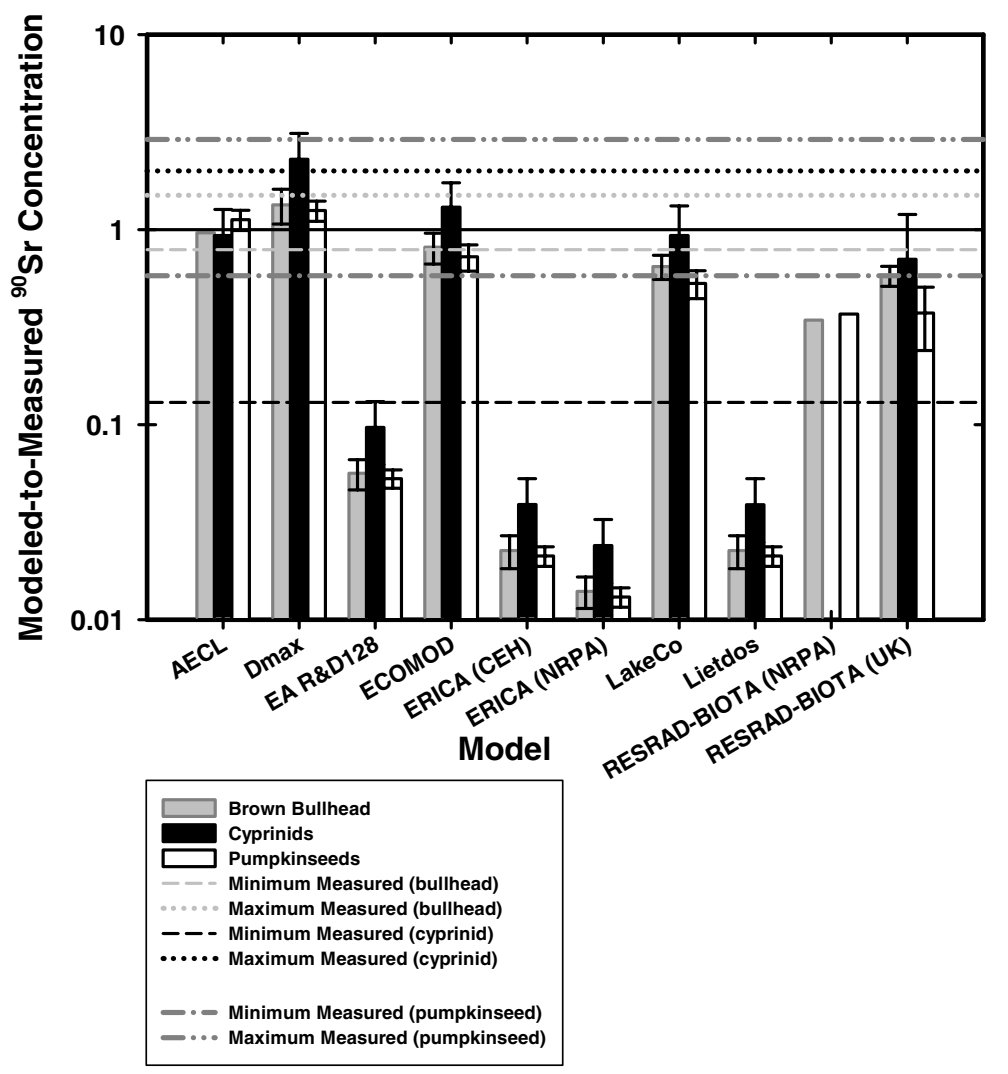

Figure 1. Comparison of modelled-to-measured ${ }^{90} \mathrm{Sr}$ concentrations for freshwater fish in Perch Lake. Dashed and dotted horizontal lines represent minimum and maximum measured values in the lake for a given type of fish species; error bars represent the standard error in predicted values for a given fish species by a given model. Note predictions by AECL, ECOMOD and D-Max were estimated taking water Ca concentration into account.

\section{RECOMMENDATIONS}

The need for a system to protect the environment from ionising radiation is now generally recognised and environmental protection is referred to in the draft revision of IAEA Basic Safety Standards and

\footnotetext{
1 Total dose rate was not evaluated for the Perch Lake scenario.
} 
new recommendations of the ICRP [1]. However, many aspects including the discussion of protection goals, agreement of benchmark values and parameterisation of models applied in the work described here are still under development.

An aim of the BWG was to improve the models used by Members States. The collaborative exercises led to the sharing of parameters and re-parameterisation by some of the participating models. However, the model-model inter-comparisons and the scenario applications only compared a limited number of radionuclides. Additionally, whilst the scenarios considered sites for which extensive databases were available, these may not, especially Chernobyl, be typical of situations needing to be assessed within regulatory frameworks.

In the near future, there are a number of international developments which will have an impact on the field of radiological protection: (i) The ICRP will deliver its framework for assessing environmental protection; (ii) The UNSCEAR will report on its review of effects data; (iii) The EC EURATOM project PROTECT will make recommendations on protection goals and numeric benchmark values (see http://www.ceh.ac.uk/protect).

These developments are all likely to impact upon any future activities of the BWG, which will continue, in some form, within the follow-up programme to EMRAS. Bearing these developments in mind, and to aid the IAEA in the development of future guidance on the radiological assessment of biota, a suggested future direction for the activities of the BWG is outlined below.

\subsection{Transfer parameters}

The work of the BWG has clearly demonstrated that the largest contribution to variability between model predictions, and comparison with available data, is the parameterisation of the models transfer components. Other studies are in agreement with this conclusion [7,8]. There is a clear need to better share knowledge on the transfer of radionuclides to biota and to provide authoritative collations of those data which are available. It is suggested that a document for biota which is equivalent to the IAEA handbook on transfer parameters for human food chains [9] should be produced.

\subsection{ICRP framework}

Outputs of the ICRP should clearly be considered by the BWG and if possible the ICRP outputs should be evaluated in any future scenario applications and model intercomparisons.

\subsection{Future scenarios}

Future scenarios should focus on situations which regulators/industry are having to consider (e.g. waste repositories, assessments for new power stations, sites contaminated by TeNORM). Such scenarios would enable the comparison of the available approaches within a regulatory context, and evaluation of the various tiers of assessment (from screening level through to detailed assessment) which the more comprehensive approaches contain. Consideration should also be given to involving more 'informed users' within the BWG rather than a predominance of model developers.

\subsection{Radiation effects data}

The models used by the BWG predict dose rates to biota, but there is also a need to define benchmark dose rates for use within assessments and be able to determine the potential consequences of predicted dose rates. A large amount of data on the effects of ionising radiation on biota has recently been collated into the FREDERICA database (see www.frederica-online.org). This compilation can be used to aid decision-making on the potential impact of predicted exposures to ionising radiation. However, the effects data available in the FREDERICA database cover only a proportion of the available scientific 
literature. Furthermore, to be of most use to decision-makers there is a need to better evaluate the quality of much of these data to ensure that they are applicable. It is suggested that this could be best achieved through a subgroup of the BWG.

Whilst approaches from chemical assessments (such as species sensitivity distributions) are being adopted in trying to define dose rate benchmarks for biota, these do not really inform us of the actual potential impact on a given species or ecosystem. It is suggested that the BWG should consider how population modelling techniques (from other fields) might be applied to aid setting thresholds against which the degree of environmental protection can be determined.

\section{References}

[1] International Commission on Radiological Protection, Recommendations of the International Commission on Radiological Protection, Publication 103, Annals of the ICRP, 37 (2007) 2-3.

[2] International Atomic Energy Agency, Environmental modelling for radiation safety (EMRAS): A summary of the outcomes of the programme (IAEA, Vienna, in press).

[3] Beresford N.A., Balonov M., Beaugelin-Seiller K., Brown J., Copplestone D., Hingston J.L., Horyna, J., Hosseini A., Howard B.J., Kamboj S., Nedveckaite T., Olyslaegers G., Sazykina T., Vives i Batlle J., Yankovich T.L. and Yu C., Appl. Radiat. Isot. Available on line: doi:10.1016/j.apradiso.2008.04.009 (2008).

[4] International Commission on Radiological Protection, The concept and use for reference animals and plants for the purposes of environmental protection (draft for discussion), J. Valentin (Ed.), ICRP Publication XX, Annals of the ICRP, Available from http://www.icrp.org/ (2005).

[5] Vives i Batlle J., Balonov M., Beaugelin-Seiller K., Beresford N.A., Brown J., Cheng J-J., Copplestone D., Doi M., Filistovic V., Golikov V., Horyna J., Hosseini A., Howard B.J., Jones S.R., Kamboj S., Kryshev A., Nedveckaite T., Olyslaegers G., Pröhl G., Sazykina T., Ulanovsky A., Vives Lynch S., Yankovich T. and Yu C., Rad. Environ. Biophys. 46 (2007) 349-373.

[6] Beresford N.A., Barnett C.L., Brown J.E., Cheng J-J., Copplestone D., Filistovic V., Hosseini A., Howard B.J., Jones S.R., Kamboj S., Kryshev A., Nedveckaite T., Olyslaegers G., Saxén R., Sazykina T., Vives i Batlle J., Vives-Lynch S., Yankovich T. and Yu C. Rad. Environ. Biophys. Submitted.

[7] Higley K.A., Domotor S.L., Antonio E.J. and Kocher D.C., J. Environ. Radioact. 66 (2003) 41-59.

[8] Avila R., Beresford N.A., Agüero A., Broed R., Brown J., Iospje M., Robles B. and Suañez A., J. Rad. Prot. 24 (2004) A105-A122.

[9] International Atomic Energy Agency, Handbook of parameter values for the prediction of radionuclide transfer in temperate environments, Technical report series 364, (IAEA, Vienna, 1994). 